\title{
Protein Misfolding and Oxidative Stress Promote Glial-Mediated Neurodegeneration in an Alexander Disease Model
}

\author{
Liqun Wang, Kenneth J. Colodner, and Mel B. Feany \\ Department of Pathology, Brigham and Women's Hospital, Harvard Medical School, Boston, Massachusetts 02115
}

\begin{abstract}
Although alterations in glial structure and function commonly accompany death of neurons in neurodegenerative diseases, the role glia play in modulating neuronal loss is poorly understood. We have created a model of Alexander disease in Drosophila by expressing disease-linked mutant versions of glial fibrillary acidic protein (GFAP) in fly glia. We find aggregation of mutant human GFAP into inclusions bearing the hallmarks of authentic Rosenthal fibers. We also observe significant toxicity of mutant human GFAP to glia, which is mediated by protein aggregation and oxidative stress. Both protein aggregation and oxidative stress contribute to activation of a robust autophagic response in glia. Toxicity of mutant GFAP to glial cells induces a non-cell-autonomous stress response and subsequent apoptosis in neurons, which is dependent on glial glutamate transport. Our findings thus establish a simple genetic model of Alexander disease and further identify cellular pathways critical for glial-induced neurodegeneration.
\end{abstract}

\section{Introduction}

Glia play critical roles in the normal functioning of the nervous system, in both vertebrates and invertebrates. However, the contribution of non-neuronal cells to neurological diseases remains underexplored. The identification of dominant mutations in the gene encoding glial fibrillary acidic protein (GFAP) in patients with Alexander disease provides a striking example of a neurological disease gene that is expressed predominantly in astrocytes (Brenner et al., 2001). Alexander disease is a rare and fatal disorder of the nervous system characterized by seizures, dysmyelination, neurodegeneration, and abnormal aggregation of GFAP into characteristic astrocytic protein aggregates termed Rosenthal fibers (Brenner et al., 2009). The dominant nature of diseasecausing mutations in the GFAP gene, together with the presence of protein aggregates in brains from affected patients, has suggested a toxic gain-of-function mechanism of disease pathogenesis, perhaps related to abnormal protein aggregation. Supporting a toxic gain-of-function model, mice overexpressing wild-type (WT) human GFAP in astrocytes develop a severe neurological syndrome leading to early death and the formation of numerous Rosenthal fibers (Messing et al., 1998), whereas mice null for GFAP are viable and healthy (Pekny et al., 1995; Liedtke et al., 1996; McCall et al., 1996; Shibuki et al., 1996). Thus, the genetic evidence suggests that either mutations in GFAP or over-

Received June 30, 2010; revised Dec. 1, 2010; accepted Dec. 19, 2010.

This work was supported by National Institutes of Health/National Institute of Neurological Disorders and Stroke Grant P01 NS042803. We thank M. Brenner, J. Goldman, and G. Tang for providing GFAP CDNAs, and R. Tanguay, D. Bohmann, S. Birman, H. Stenmark, and S. Sigrist for transgenic fly lines. We benefited from helpful discussions with M. Brenner, J. Goldman, A. Messing, and M. Nedergaard.

Correspondence should be addressed to Mel B. Feany, Department of Pathology, Brigham and Women's Hospital, 77 Louis Pasteur Avenue, Room 630, Boston, MA 02115. E-mail: mel_feany@hms.harvard.edu.

DOI:10.1523/JNEUROSCI.3410-10.2011

Copyright $\odot 2011$ the authors $\quad 0270-6474 / 11 / 312868-10 \$ 15.00 / 0$ expression of the wild-type protein can induce abnormal aggregation of the protein and concomitant cellular toxicity.

Although the precise nature of the gain-of-function toxicity of GFAP awaits definition, experimental evidence now supports a role for abnormal aggregation of the glial intermediate filament protein in Alexander disease pathogenesis. Overexpression of the small heat shock protein ( $\mathrm{Hsp}$ ) and Rosenthal fiber constituent Cryab ( $\alpha \mathrm{B}$-crystallin) rescues toxicity and decreases aggregation of GFAP in mice, whereas reducing levels of endogenous Cryab exacerbates toxicity (Hagemann et al., 2009). Both oxidative stress and reduction in glial glutamate transporter mRNA are also observed in GFAP transgenic mouse models of Alexander disease (Hagemann et al., 2006, 2009; Tian et al., 2010). Cellular models and in vitro work have additionally provided important clues to the pathogenesis of Alexander disease and support a critical role for abnormalities of protein degradation pathways, including the proteasome and autophagy in Alexander disease (Tang et al., 2006, 2008, 2010).

To enable a comprehensive genetic analysis of Alexander disease, we have created a Drosophila model based on expression of human GFAP in glial cells. We find robust accumulation of glial inclusions similar to authentic Rosenthal fibers and accompanying glial toxicity. We also replicate non-cell-autonomous neuronal cell death, a poorly understood feature of Alexander disease. Using the genetic tools available in Drosophila, we provide evidence that protein misfolding and oxidative stress play an important role in cellular toxicity in vivo. We further find that GFAP aggregation and oxidative stress promote autophagy and JNK (c-Jun N-terminal protein kinase) pathway activation in both neurons and glial cells. Thus, we show here that our genetic model bears key similarities to vertebrate models of Alexander disease, and we dissect the mechanisms responsible for the neural-glial interplay leading to neuronal death in the disorder. 
A
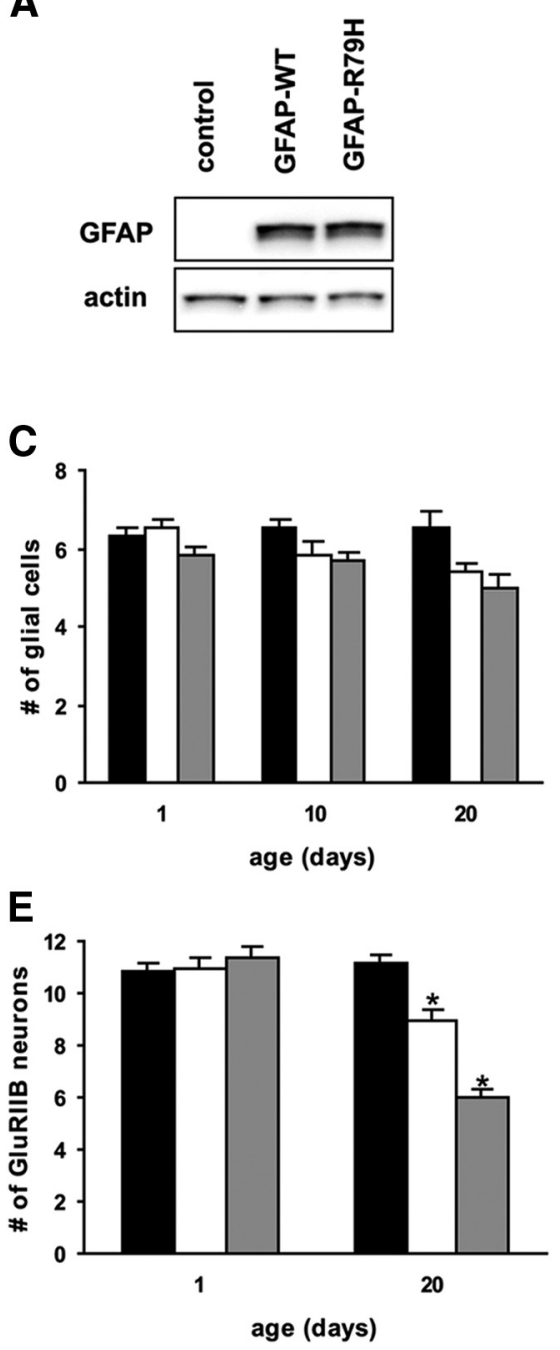

B

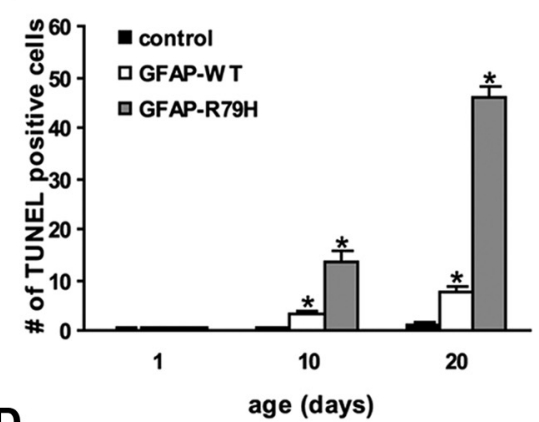

D

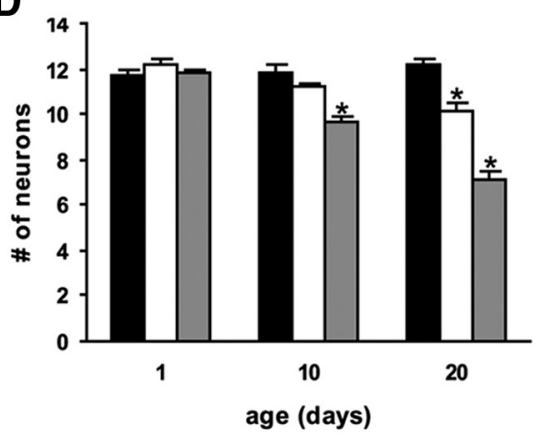

$\mathbf{F}$

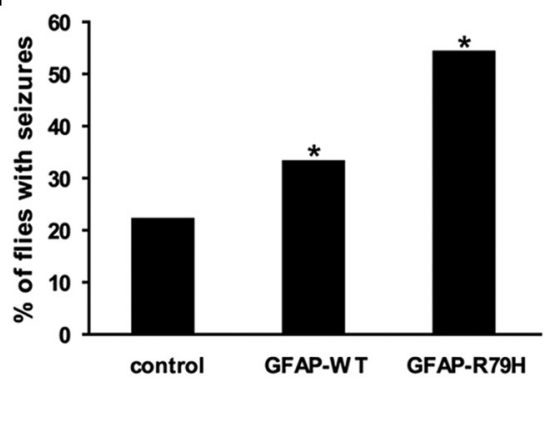

Figure 1. Expression of human GFAP in Drosophila produces cell death and seizures. $\boldsymbol{A}$, Western blot showing equivalent levels of expression of GFAP ${ }^{\text {WT }}$ and GFAP ${ }^{\mathrm{R} 79 H}$ (top). The blot was reprobed with an antibody to actin to demonstrate equivalent protein loading (bottom). Flies are $1 \mathrm{~d}$ old. $\boldsymbol{B}$, The number of TUNEL-positive cells increases with age and expression of mutant GFAP in glial cells. $n=6$ for each genotype and time point. Serial frontal sections of the entire brain (central body and medulla) were assayed. ${ }^{*} p<0.01$ versus control. $C$, There is a trend toward decreasing numbers of glial cells with advancing age ( $p=0.012$, control vs GFAP $^{\mathrm{R} 79 \mathrm{H}}$ at $20 \mathrm{~d}$ ). $n=6$ for each genotype. $\mathrm{A} 20 \mu \mathrm{m}$ region of lamina was assayed. $\boldsymbol{D}$, The number of neurons decreases with age and expression of mutant GFAP in glial cells. $n=6$ for each genotype. A $20 \mu \mathrm{m}$ region of lamina was assayed. ${ }^{*} p<0.01$ versus control. $\boldsymbol{E}$, The number of GluRIIB neurons decreases in aged GFAP transgenic flies. At day 20, there is a significant loss of GFPlabeled GluRIIB neurons in both GFAP WT and GFAP ${ }^{\mathrm{R79H}}$ flies. GFAP ${ }^{\mathrm{R} 79 \mathrm{H}}$ has more severe loss of GluRIIB neurons than GFAP WT $n=$ 6 for each genotype. A $20 \mu \mathrm{m}$ region of lamina was assayed. ${ }^{*} p<0.01$ versus control. $\boldsymbol{F}$, There is increased seizure frequency in GFAP transgenic flies as demonstrated by the percentage of flies exhibiting seizures after mechanical stimulation. Flies are $1 \mathrm{~d}$ old. $n=90$ for each genotype. ${ }^{*} p<0.01$ versus control. Genotypes are as follows: control: repo-GAL4/+; GFAP WT: repo-GAL4, UAS-GFAP $P^{W T}+$; GFAP ${ }^{\mathrm{R} 79 \mathrm{H}}:$ repo-GAL4, UAS-GFAP $P^{R 79 H} /+$.

\section{Materials and Methods}

Drosophila stocks and genetics. Human wild-type or mutant $(\mathrm{R} 79 \mathrm{H}$, R239C, R239H, L352P, A364P) GFAP was expressed under the control of the galactosidase-4 (GAL4)/upstream activating sequence (UAS) system (Brand and Perrimon, 1993) using the repo-GAL4 driver (Sepp and Auld, 1999) to mediate expression in glia. Fly crosses were performed at $25^{\circ} \mathrm{C}$, and animals were aged at $29^{\circ} \mathrm{C}$ to increase transgene expression. Equal numbers of males and females were used in all experiments. Substantial sex-related phenotypic differences were not observed. Other fly stocks used include the following: UAS-Cryab (UAS-l(2)efl) (D. Bohmann, University of Rochester Medical Center, Rochester, NY), UAS-Eaat1 (S. Birman, Paris Tech, Paris, France), UAS-GFP-LC3 (H. Stenmark, Oslo University, Oslo, Norway), GluRIIB ${ }^{G F P}$ (S. Sigrist, Freie Universität, Berlin, Germany), UAS-hSod1 (our laboratory), UAS-Cat, UAS-lacZ, puckered
(puc)-lacZ, $\mathrm{Cat}^{-1-}\left(\mathrm{Cat}^{n 1}\right), \mathrm{Sod}^{-/-}\left(\mathrm{Sod}^{n 1}\right)$, UAS-hHsp70, $w^{1118}$ (Bloomington Drosophila Stock Center).

Drug feedings. For 17-AAG [17-(allylamino)17-demethoxygeldanamycin] feeding, 1-d-old flies were fed a final concentration of $10 \mu \mathrm{g} / \mathrm{ml}$ 17-AAG (InvivoGen), which had been dissolved in DMSO and mixed with standard cornmeal medium. Control flies were fed equal volume of DMSO, which was mixed with standard cornmeal medium. For vitamin E feeding, 1-d-old flies were fed a final concentration of 0.5 or 1.5 mM $\alpha$-tocopherol (Sigma-Aldrich), which had been dissolved in soybean oil and mixed with standard cornmeal medium. Control flies were fed equal volume of soybean oil, which was mixed with standard cornmeal medium. Drug and control fed flies were transferred to new drug-embedded food every $3 \mathrm{~d}$.

Behavioral analysis. Flies were collected under $\mathrm{CO}_{2}$ anesthesia at $1 \mathrm{~d}$ after eclosion and kept at three animals per vial for $1 \mathrm{~d}$ without additional anesthesia before analysis. For testing, vials were mechanically stimulated on a VWR mini vortexer for $10 \mathrm{~s}$ at the maximum speed (Ganetzky and $\mathrm{Wu}, 1982$; Song et al., 2008). The number of flies showing seizures was recorded, and the seizure frequency was calculated by dividing the number of flies with seizures by the total number of flies analyzed. Statistical analysis was performed using the $\chi^{2}$ test.

Immunohistochemistry, immunofluorescence, and terminal deoxynucleotidyl transferasemediated biotinylated UTP nick end labeling analysis. For paraffin histology and immunostaining, adult flies were fixed in Formalin and embedded in paraffin. Four micrometer serial frontal sections were prepared through the entire fly brain. Slides were processed through xylene, ethanol, and into water. Antigen retrieval by boiling in sodium citrate, $\mathrm{pH}$ 6.0, was used before immunostaining on paraffin sections. In some studies, fresh brains were fixed directly in Formalin or methanol. Slides were blocked in PBS containing 0.3\% Triton X-100 and $2 \%$ milk for $1 \mathrm{~h}$. Immunostaining was performed using the following primary antibodies at the specified dilutions: anti-GFAP (rabbit, 1:5000, Dako; CA; mouse, 1:1000, Neomarker), anti-Cryab (rabbit, 1:50; Stressgen), anti- $\beta$-galactosidase (mouse, $1: 500$; Promega), anti-repo (mouse, 1:25; Developmental Studies Hybridoma Bank), anti-elav (mouse, 1:10; Developmental Studies Hybridoma Bank), and anti-green fluorescent protein (GFP) (mouse, 1:10; Antibodies Inc.). For immunohistochemistry, biotin-conjugated secondary antibodies (1:200; Southern Biotechnology) and avidin-biotin-peroxidase complex (Vectastain Elite; Vector Laboratories) staining was performed using DAB (Sigma-Aldrich) as a chromagen. For double-labeling studies, secondary antibodies coupled to Alexa Fluor 488 or Alexa Fluor 555 (1:200; Invitrogen) were used.

Apoptotic cell death was visualized using terminal deoxynucleotidyl transferase-mediated biotinylated UTP nick end labeling (TUNEL) according to the instructions of the manufacturer (TdT FragEL DNA fragmentation kit; Calbiochem), with an additional avidin-biotin-peroxidase amplification step.

The number of TUNEL-positive cells (see Figs. $1 B, 3 A, 4 A, 5 A, 6 A, 7$ ) (supplemental Fig. $4 A$, available at www.jneurosci.org as supplemental material) and $\beta$-galactosidase-positive cells (see Fig. $8 \mathrm{~A}, \mathrm{~J}$ ) was counted 
by examining serial frontal sections $(4 \mu \mathrm{m})$ of the entire brains (central body and medulla) from at least six animals per genotype and time point. Quantification of glial cells, neurons, and GluRIIB neurons (see Fig. $1 C-E$ ) was performed by counting the positive cells in a consistent $20 \mu \mathrm{m}$ region of lamina from at least six animals per genotype and time point. Statisti$\mathrm{cal}$ analysis was performed using ANOVA with Tukey-Kramer post hoc test for multiple comparisons. Each data point represents the mean \pm SEM.

Inclusion density in GFAP transgenic flies expressing either GFAP ${ }^{\mathrm{WT}}$ or GFAP ${ }^{\mathrm{R} 79 \mathrm{H}}$ in glial cells was calculated as the percentage of cell cortex (in the Kenyon cell region) occupied by GFAP-immunoreactive inclusion bodies on DAB-stained paraffin tissue sections using NIH Image in at least six animals per genotype and time point (see Figs. $2 K, 3 C, 4 C, 5 C, 6 C$ ). Statistical analysis was performed using ANOVA with Tukey-Kramer post hoc test for multiple comparisons. Each data point represents the mean \pm SEM.

Western blots. For standard Western blot analysis, adult Drosophila heads were homogenized in $1 \times$ Laemmli's buffer (Sigma-Aldrich). For determination of soluble and insoluble GFAP, the extraction method of Der Perng (2006) was used. Adult fly heads were homogenized in extraction buffer containing $20 \mathrm{~mm}$ Tris-HCl, pH 7.6, 140 mм NaCl, 5 mм EDTA, 1 mM EGTA, 1\% (v/v) NP-40, and 0.5\% (w/v) sodium deoxycholate supplemented with a protease inhibitor cocktail. The homogenates were centrifuged at $16,000 \times g$ for $15 \mathrm{~min}$ at $4^{\circ} \mathrm{C}$, and pellets were washed sequentially with pelleting buffer (in mM: 20 Tris- $\mathrm{HCl}, \mathrm{pH} 8.0$, $10 \mathrm{MgCl}_{2}$, and $1 \mathrm{PMSF}$ ) and PBS containing 1 mM PMSF. The final pellets were resuspended in Laemmli's sample buffer and considered as insoluble fractions. The supernatants were considered as soluble fractions. One fly head equivalent of soluble and insoluble fractions was used for analysis. Samples were boiled for $10 \mathrm{~min}$, briefly centrifuged, and subjected to SDS-PAGE in 10\% separating gels (Cambrex). Proteins were transferred to nitrocellulose membranes (Bio-Rad), blocked in $2 \%$ milk in PBS with $0.05 \%$ Tween 20 , and immunoblotted using one of the following antibodies: antiGFAP (1:107 ; Dako), anti-actin (1:50,000; Sigma-Aldrich), or anti-GFP (1:1000; Antibodies Inc.). The appropriate anti-mouse or anti-rabbit horseradish peroxidase-conjugated secondary antibody (1:50,000; Southern Biotechnology) was applied, and signal was detected by chemiluminescence (Alpha Innotech). Ponceau S staining was used to monitor protein transfer. All blots were repeated at least three times, and representative blots are presented in the figures.

Electron microscopy. Brains from 20-d-old glial GFAP transgenic and control flies were dissected out of the cuticle and fixed in $2.5 \%$ glutaraldehyde (Polysciences). Brains were then incubated in $1 \%$ osmium tetroxide (Electron Microscopy Sciences) $1.5 \%$ potassium ferrocyanide (MP Biomedicals) for $1 \mathrm{~h}, 1 \%$ uranyl acetate for $30 \mathrm{~min}$, and then processed through 70, 90, and 100\% ethanol solutions. Brains were then incubated in propyleneoxide for $1 \mathrm{~h}$, embedded in Epon, and allowed to polymerize for $2 \mathrm{~d}$ at $60^{\circ} \mathrm{C}$. Thin sections were cut and examined with a Tecnai $\mathrm{G}^{2}$ Spirit BioTWIN transmission electron microscope at an accelerating voltage of $80 \mathrm{kV}$.

\section{Results}

We postulated a toxic dominant mechanism, perhaps related to abnormal GFAP aggregation, in Alexander disease. We therefore modeled the disorder by expressing wild-type and disease-linked mutant versions of GFAP in Drosophila using the GAL4/UAS modular expression system (Brand and Perrimon, 1993). In our experiments, we express wild-type and mutant human GFAP in glial cells using the repo-GAL4 driver (Sepp et al., 2001). To begin modeling Alexander disease in flies, we cloned human wild-type $\left(\right.$ GFAP $^{\text {WT }}$ ) and mutant forms of human GFAP downstream of binding sites for GAL4 in the pUAST Drosophila expression vector. Human GFAP cDNAs, including wild-type GFAP and a clone carrying the Alexander disease-associated mutation R79H, were obtained from J. Goldman (Columbia University, New York, NY). Embryos were injected, and transgenic flies carrying inser- 
A
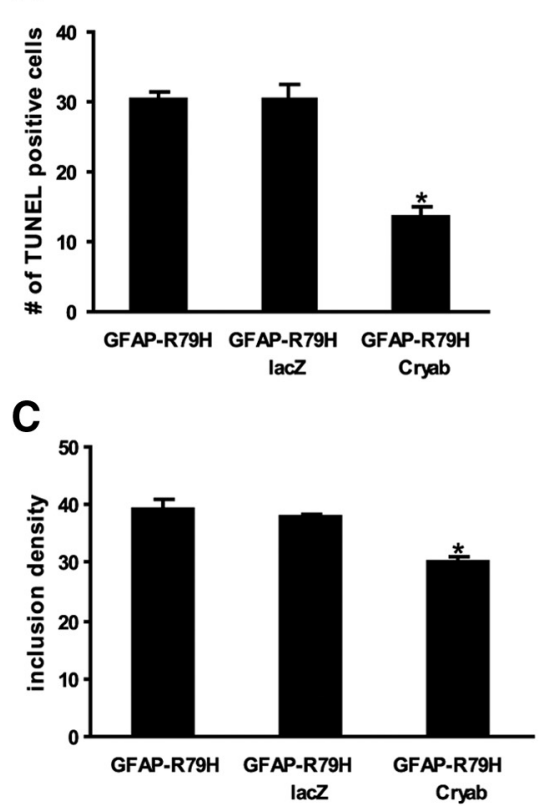

Figure 3. Cryab overexpression rescues GFAP toxicity and aggregation. $A$, Decreased numbers of TUNEL-positive cells are present when GFAP ${ }^{\mathrm{R} 79 \mathrm{H}}$ is coexpressed with Drosophila Cryab. Flies are $20 \mathrm{~d}$ old. $n=6$ for each genotype. ${ }^{*} p<0.01$ versus $\mathrm{GFAP}^{\mathrm{R} 79 \mathrm{H}} / \mathrm{lacZ}$. B, Overexpression of Cryab in GFAP ${ }^{\mathrm{R} 7 \mathrm{H}}$ flies reduces the percentage of flies with seizures. Flies are $1 \mathrm{~d}$ old. $n=90$ $\left(\right.$ GFAP $^{\mathrm{R} 79 \mathrm{H}}$ ) and $n=144$ (GFAP $\left.{ }^{\mathrm{R} 79 \mathrm{H}} / \mathrm{Cryab}\right){ }^{*} p<0.01$. C, Decreased numbers of GFAP-immunoreactive inclusions are present when GFAP ${ }^{\mathrm{R} 79 \mathrm{H}}$ is coexpressed with Drosophila Cryab. Flies are $20 \mathrm{~d}$ old. $n=6$ for each genotype. ${ }^{*} p<0.01$ versus GFAP ${ }^{\mathrm{R} 79 H} / \mathrm{lacZ}$. $D$, verexpression of Cryab in glia of GFAP transgenic flies increases GFAP solubility compared with GFAP ${ }^{\mathrm{R} 7 \mathrm{H}}$ alone (GFAP ${ }^{\mathrm{R} 79 H}$, lacZ), without changing the total GFAP level (top). Flies are $1 \mathrm{~d}$ old. The blot was reprobed with an antibody to actin to demonstrate equivalent protein loading (soluble fractions; bottom). Genotypes are as follows: control: repo-GAL4/+; GFAP ${ }^{\text {R79H: }}$ repo-GAL4, UAS-GFAP $P^{R 79 H} /+$; GFAP ${ }^{R 79 H} /$ lacZ: repo-GAL4, UAS-GFAPR79H / ; UAS-lacZl+; GFAP R79H/Cryab: repo-GAL4, UASGFAP $P^{R 79 H} /+$; UAS-Cryab/+.

tions of the GFAP transgenes were isolated. We recovered at least five independent insertion lines for each of the constructs. GFA$\mathrm{P}^{\mathrm{WT}}$ and GFAP ${ }^{\mathrm{R} 79 \mathrm{H}}$ transgenic lines with equivalent levels of expression as determined by Western blot analysis were selected (Fig. $1 A$ ) and used in subsequent analyses.

When wild-type and mutant versions of GFAP were expressed in glial cells (repo-GAL4 driver), flies eclosed at the expected frequency, consistent with normal development. Overall brain structure appeared normal at $1 \mathrm{~d}$ of age as assayed by hematoxylin and eosin (H\&E) staining of serial sections through the entire brain (data not shown). The TUNEL assay has been widely used to identify cells dying by apoptosis in vertebrate tissue and in fly models of human neurological diseases as well (Ghosh and Feany, 2004; Khurana et al., 2006). When we performed TUNEL staining at $1 \mathrm{~d}$ of age in our GFAP transgenic flies, we did not identify any dying cells. However, increasing numbers of TUNEL-positive cells were seen as the animals aged (Fig. $1 B$ ). The TUNEL-positive cells were widespread, with no obvious predilection for particular areas of the brain (data not shown). The widespread pattern of cell death is consistent with the expression of repo-driven GAL4 in the majority of glial cells throughout the brain (Sepp et al., 2001). Mutant GFAP (GFAP ${ }^{\text {R79H }}$ ) was significantly more toxic than the wild-type protein (GFAP ${ }^{\mathrm{WT}}$ ). However, wild-type GFAP did exhibit limited toxicity, consistent with the phenotypes seen in transgenic mice expressing wild-type human GFAP described by the Messing laboratory (Messing et al., 1998).

To determine the cell type(s) affected in our GFAP transgenic flies, we assessed the numbers of neurons and glia over time in the brains of our GFAP transgenic flies using antibodies specific to neurons (anti-elav) and glia (anti-repo). We focused on the lamina because the lamina is a wellordered area of the fly brain amenable to quantitative analysis and because our analysis of $\mathrm{H} \& \mathrm{E}$-stained sections (data not shown) suggested significant pathology in the lamina. We found a trend toward decreased numbers of glial cells with advancing age (Fig. 1C) and a significant loss of neurons at 10 and $20 \mathrm{~d}$ of age (Fig. 1D), consistent with a non-cellautonomous effect of expressing GFAP in glial cells. Colocalization of TUNELpositive cells with glial cell marker (anti-repo) and neuronal cell marker (anti-elav) confirms the cell death of both glia and neurons in mutant GFAP flies (supplemental Fig. 1, available at www. jneurosci.org as supplemental material). These findings support a loss of neurons secondary to glial dysfunction induced by expression of GFAP. Although Alexander disease is known for white matter loss, neurodegeneration is also a consistent feature of the disorder (van der Knaap et al., 2005; Brenner et al., 2009).

Because abnormalities of glial glutamate transport have been suggested in $\mathrm{Al}$ exander disease model mice (Hagemann et al., 2009; Tian et al., 2010), we determined whether neurons expressing glutamate receptors (GluRs) were susceptible to the toxicity induced by GFAP expression in glial cells. Using a GFP-labeled GluRIIB subunit under the control of its endogenous promotor (Schmid et al., 2008), we observed a significant loss of neurons expressing glutamate receptors (Fig. 1E) when $\mathrm{GFAP}^{\mathrm{R} 79 \mathrm{H}}$ was expressed in glial cells. Expression of GFAP ${ }^{\mathrm{WT}}$ in glial cells also promoted loss of GluRIIB-expressing neurons, albeit to a lesser extent. We do not have reagents that identify all glutamate receptors in Drosophila, and we are thus unable to determine whether glutamate receptor-expressing neurons are more sensitive to GFAP toxicity compared with glutamate receptor-negative neurons.

Seizures are common in patients with Alexander disease (Brenner et al., 2009). To assess the functional consequence of human GFAP expression in Drosophila glial cells, we determined the percentage of flies exhibiting seizures in response to mechanical stimulation, a commonly used seizure paradigm in flies (Benzer, 1971; Ganetzky and Wu, 1982). We found significantly increased seizure frequency in flies expressing either GFAP ${ }^{\mathrm{WT}}$ or GFAP $^{\mathrm{R} 79 \mathrm{H}}$ (Fig. $1 \mathrm{~F}$ ). As in other assays of cellular toxicity (Fig. $1 B-E)$, mutant GFAP (GFAP ${ }^{\mathrm{R} 79 \mathrm{H}}$ ) was more toxic than the wildtype protein.

To determine whether functional abnormalities and neurodegeneration were accompanied by abnormal protein aggregation, a key feature of Alexander disease, sections from flies expressing human GFAP ${ }^{\text {WT }}$ or GFAP ${ }^{\mathrm{R} 79 \mathrm{H}}$ were prepared. A standard hematoxylin and eosin stain revealed only normal background neuropil in control flies (Fig. 2A; genotype: repo-GAL4/+), whereas numerous eosinophilic, elongated and beaded inclusions were seen in GFAP ${ }^{\mathrm{R} 79 \mathrm{H}}$ transgenic flies (Fig. $2 \mathrm{~B}$, arrows). By electron 
microscopy, inclusions were present within the cytoplasm of glial cells, as recognized by their characteristic electrondense cytoplasm. Inclusions were osmiophilic and granular and were not membrane bound (Fig. 2C, arrow) (supplemental Fig. 2, arrows, available at www.jneurosci.org as supplemental material). Paraffin sections were next immunostained with an antibody that recognizes GFAP. No immunoreactivity was seen in control flies (Fig. 2D), whereas flies expressing GFAP ${ }^{\mathrm{WT}}$ showed immunostaining predominantly highlighting normal, thin glial processes (Fig. $2 E$, arrowheads). In contrast, numerous round to elongated inclusions were present in flies expressing GFAP ${ }^{\mathrm{R} 79 H}$. Inclusions were present in a widespread pattern throughout the neuropil and cortex, consistent with the expression of repo-driven GAL4 in the majority of glial cells throughout the brain (Sepp et al., 2001) (Fig. 2F) (supplemental Fig. 3, arrows indicate representative inclusions, available at www. jneurosci.org as supplemental material). Inclusions also contained the small heat shock protein Cryab as demonstrated by double-label immunofluorescence using an antibody recognizing Drosophila Cryab (Fig. 2G-J, arrow). These light and electron microscopic features are all highly reminiscent of authentic Rosenthal fibers from patients with Alexander disease.

We next examined the number of inclusions present as transgenic animals aged (Fig. $2 \mathrm{~K}$ ). We found that inclusions were present at $1 \mathrm{~d}$ of age in flies expressing GFAP ${ }^{\mathrm{R} 79 \mathrm{H}}$. Significant additional accumulation of inclusion bodies occurred by 10 and $20 \mathrm{~d}$ of age. Many fewer inclusions were detected in flies expressing GFAP ${ }^{\mathrm{WT}}$, although the number did increase with age. Similar to transgenic mice (Messing et al., 1998), GFAP ${ }^{\mathrm{WT}}$ does have the potential to form inclusions in our model as also evidenced by more robust formation of inclusions in flies expressing higher levels of GFAP WT (data not shown).

To characterize GFAP aggregation further, soluble and insoluble fractions were prepared from transgenic flies expressing GFAP ${ }^{\mathrm{WT}}$ or GFAP ${ }^{\mathrm{R} 79 \mathrm{H}}$ using deoxycholate-containing extraction buffer, which solubilizes nearly all wild-type GFAP but little mutant GFAP expressed in human glioma cells (Der Perng et al., 2006). Similar to their findings, immunoblotting analysis revealed significantly more GFAP in the insoluble fraction from flies expressing GFAP ${ }^{\mathrm{R} 79 \mathrm{H}}$ compared with flies expressing GFAP ${ }^{\mathrm{WT}}$ (Fig. 2L). The pool of soluble GFAP ${ }^{\mathrm{R} 79 \mathrm{H}}$ was modestly decreased compared with GFAP ${ }^{\mathrm{WT}}$ as well, consistent with conversion of soluble GFAP into insoluble species.

To begin to define the pathways mediating toxicity in our model and to make key analogies between pathogenic pathways in flies and vertebrate systems, we have tested candidate genetic modifiers of GFAP toxicity. Cryab is an effective modulator of GFAP toxicity and aggregation in transgenic mice (Hagemann et al., 2009). We thus tested the ability of the Drosophila homolog of Cryab (also known as 1(2)efl; here termed Cryab for GFAP $^{R 79 H} /+; U A S-h H s p 70 /+$.
B

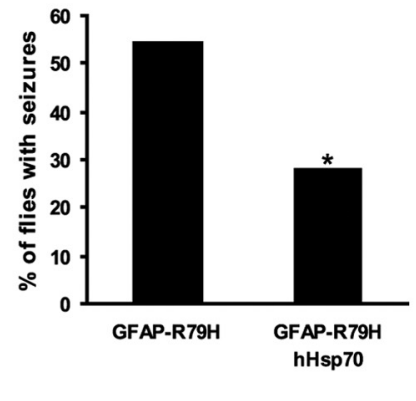

D

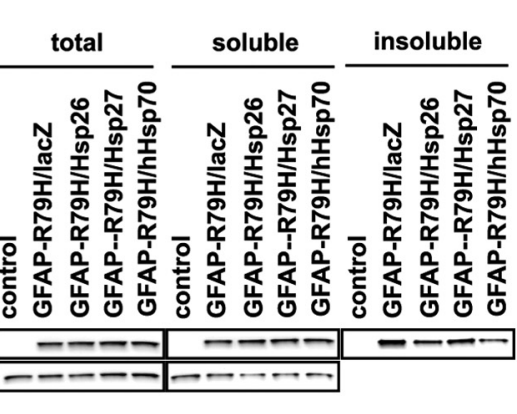

Figure 4. Overexpression of other chaperones also rescues GFAP toxicity and aggregation. $\boldsymbol{A}$, Decreased numbers of TUNELpositive cells are present when GFAP ${ }^{\mathrm{R} 79 H}$ is coexpressed with Hsp26, Hsp27, or human Hsp70. Flies are $20 \mathrm{~d}$ old. $n=6$ for each GFAP-immunoreactive inclusions are present when GFAP ${ }^{\text {R79H }}$ is coexpressed with Hsp26, Hsp27, or human Hsp70. Flies are $20 \mathrm{~d}$ GFAP $^{R 79 H} /+$; GFAP ${ }^{\mathrm{R} 79 H} / \mathrm{lacZ}$ : repo-GAL4, UAS-GFAP $P^{R 79 H} /+$; UAS-lacZI+; GFAP R79H/Hsp26: repo-GAL4, UAS-GFAP ${ }^{R 79 H} /+$

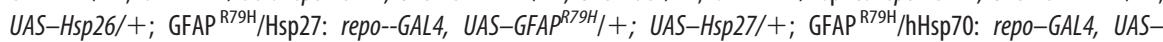

clarity) to modify toxicity and aggregation in our system. When we overexpressed Drosophila Cryab [UAS-l(2)efl] (Wang et al., 2005 ) in flies expressing GFAP ${ }^{\mathrm{R} 79 \mathrm{H}}$, we found a significant reduction in cell death as determined by TUNEL assay (Fig. $3 A$ ). In Figure $3 A$ and subsequent modifier analyses, a nontoxic transgene (UAS-lacZ, encoding $\beta$-galactosidase) is used to control for nonspecific effects of expression of a second, unrelated transgene. In addition to reducing cell death, expression of Cryab also decreased the numbers of seizures (Fig. $3 B$ ). Protection from cellular toxicity was accompanied by a significant reduction in the number of inclusion bodies (Fig. 3C). Although total levels of GFAP were not changed by expressing Cryab, the levels of insoluble GFAP as determined biochemically were reduced with coexpression of Cryab (Fig. 3D).

To explore a possible general role for protein misfolding in GFAP toxicity, we expressed additional small heat shock proteins (Hsp26, Hsp27) as well as human Hsp70 together with GFAP. We found that expression of Hsp26, Hsp27, or human Hsp70 significantly ameliorated toxicity in our GFAP transgenic animals (Fig. $4 A, B)$. As for Cryab expression, expression of the other heat shock proteins also reduced inclusion number (Fig. 4C) and formation of insoluble GFAP (Fig. 4D).

Toxicity of reactive oxygen species is commonly implicated in the pathogenesis of neurological disorders. To determine whether oxidative stress plays a causal role in GFAP toxicity, we manipulated levels of catalase (Cat) and superoxide dismutase (Sod). Overexpres- 
A

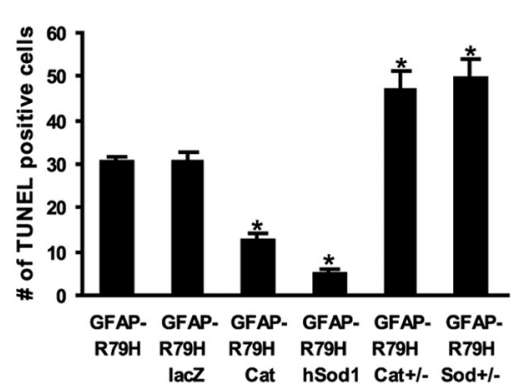

C

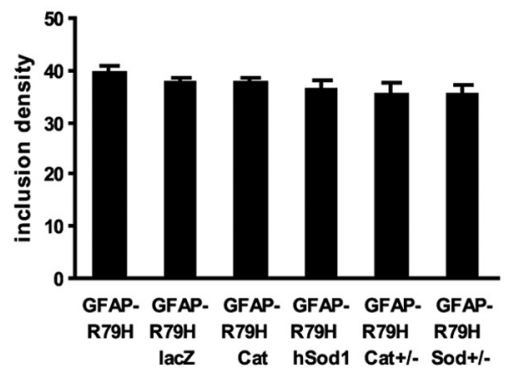

B

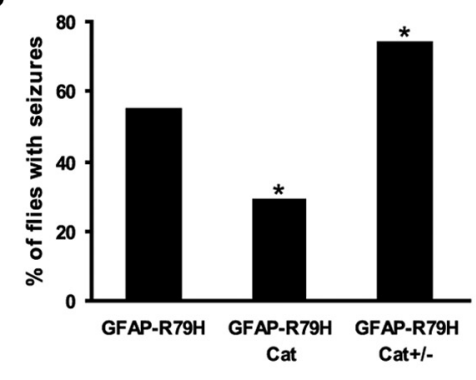

D

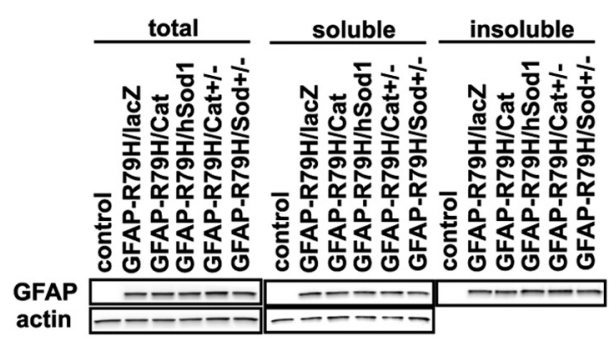

Figure 5. Levels of antioxidant proteins influence GFAP toxicity but do not change GFAP solubility. $\boldsymbol{A}$, Increasing Cat levels or expressing human Sod1 reduces the number of TUNEL-positive cells, whereas reducing levels of Cat or Sod using heterozygous null alleles of Cat and Sod increases TUNEL-positive cells. Flies are $20 \mathrm{~d}$ old. $n=6$ for each genotype. ${ }^{*} p<0.01$ versus controls (GFAP $^{\mathrm{R} 79 \mathrm{H}}$ and GFAP ${ }^{\mathrm{R79H}} / \mathrm{lacZ}$ ). $B$, Overexpression of Cat in glia of GFAP ${ }^{\mathrm{R79H}}$ flies (GFAP ${ }^{\mathrm{R} 79 \mathrm{H}} / \mathrm{Cat}$ ) reduces the percentage of flies with seizures, whereas reducing Cat using heterozygous null allele of Cat increases seizures. Flies are $1 \mathrm{~d}$ old. $n=90$ (control and $\left.\mathrm{GFAP}^{\mathrm{R79H}}\right), n=212\left(\mathrm{GFAP}^{\mathrm{R} 79 \mathrm{H}} / \mathrm{Cat}\right)$, and $n=135\left(\mathrm{GFAP}^{\mathrm{R} 79 \mathrm{H}} / \mathrm{Cat}^{+/-}\right){ }^{*} p<0.01$. C, 0xidative stress modifiers do not influence inclusion number. Flies are $20 \mathrm{~d}$ old. $n=6$ for each genotype. $D, 0$ verexpression of Cat or human Sod 1, or reducing Cat or Sod using heterozygous null alleles of Cat and Sod in glia of GFAP transgenic flies does not change GFAP solubility compared with GFAP ${ }^{\mathrm{R} 79 H}$ alone (top). Flies are $1 \mathrm{~d}$ old. The blot was reprobed with an antibody to actin to demonstrate equivalent protein loading (soluble fractions; bottom). Genotypes are as follows: control: repo-GAL4/+; GFAP ${ }^{\mathrm{R} 79 \mathrm{H}}$ : repo-GAL4, UAS-GFAP ${ }^{R 79 H} /+$; GFAP ${ }^{\mathrm{R} 79 \mathrm{H}} / \mathrm{lacZ}$ : repo-GAL4, UAS-GFAP ${ }^{R 79 H} /+$; UAS-lacZ/+; GFAP R79H/Cat: repo-GAL, UAS-GFAP $P^{R 79 H} /+$; UAS-Cat/+ ; GFAP ${ }^{\mathrm{R} 79 H} / \mathrm{hSOd1}$ : re-

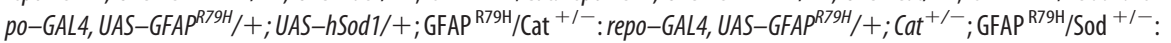
repo-GAL4, UAS-GFAP $P^{R 79 H} /+;$ SOd $^{+/-}$.

sion of either Cat or human Sod1 decreased GFAP toxicity (Fig. 5A). Conversely, reducing catalase or endogenous Sod expression levels by $\sim 50 \%$ by removing one copy of the Cat or Sod genes significantly enhanced GFAP toxicity (Fig. 5A,B). Removing one copy of the Cat or Sod genes themselves has no toxicity on flies (data not shown). To explore the mechanism by which altering antioxidant defense mechanisms influences GFAP toxicity, we determined the effects of manipulating Cat and Sod1 on inclusion formation. Unlike the chaperone modifiers, we found that oxidative stress modifiers did not significantly alter the number of inclusions present in our GFAP transgenic animals (Fig. 5C) or influence biochemical solubility of GFAP (Fig. 5D).

Alterations in the uptake of the excitatory neurotransmitter glutamate by glial cells have been implicated in glial-cell mediated neurotoxicity (Rothstein, 2009). Drosophila have a single highaffinity glutamate transporter [Eaat1 (excitatory amino acid transporter 1)] that is localized to glial processes adjacent to synapses (Seal et al., 1998; Rival et al., 2004). To determine whether the ability of glial cells to transport glutamate influences GFAP toxicity in our transgenic flies, we overexpressed the Drosophila glial glutamate transporter Eaat1 in fly glia. We found significant rescue of GFAP toxicity when we increased levels of the glutamate transporter (Fig. 6A,B) (supplemental Fig. 4, available at www. jneurosci.org as supplemental material). Similar to oxidative stress modifiers, overexpression of Eaat1 did not influence inclusion formation or GFAP solubility (Fig. 6C,D).
The ultimate goal of our work is the development of effective therapies for patients with Alexander disease. To explore the potential of the protein folding and oxidative stress pathways as therapeutic targets, we fed flies compounds influencing these pathways and assessed toxicity of GFAP in drug-fed flies. We found that administration of the compound 17-AAG, an Hsp90 inhibitor known to cross the blood-brain barrier and induce degradation of client proteins (Waza et al., 2006; Fujikake et al., 2008), significantly reduced cellular toxicity (Fig. 7A). Similarly, toxicity was reduced substantially when the antioxidant vitamin $\mathrm{E}$ was administered in Drosophila medium (Fig. 7B).

Oxidative stress is commonly linked with activation of the JNK pathway. In Drosophila, the puc-lacZ reporter provides a convenient readout of JNK activation (Martín-Blanco et al., 1998). When we immunostained brains of GFAP transgenic flies for $\beta$-galactosidase, we saw significant activation of the reporter gene, particularly in older animals. Activation was greater in flies expressing GFAP ${ }^{\mathrm{R} 79 \mathrm{H}}$ compared with GFAP ${ }^{\mathrm{WT}}$ transgenic flies (Fig. 8A). To identify the cells with JNK activation, we used double-label immunofluorescence together with markers of glia (anti-repo) and neurons (anti-elav). We found JNK activation in both glia and neurons (Fig. $8 B-I$, arrows). To determine the time course of JNK activation in neurons and glia, we determined the percentage of $\beta$-galactosidase that were neurons or glia with age (Fig. $8 J$ ). We observed proportionally more neurons showing upregulation of each pathway with disease progression.

Activation of autophagy has been linked to both accumulation of misfolded proteins and oxidative stress (Azad et al., 2009; GarcíaArencibia et al., 2010). We determined with autophagy was induced in our Drosophila model by assaying the levels of a GFP-LC3 reporter (Rusten et al., 2004). We found significantly increased levels of the reporter when either GFAP ${ }^{\mathrm{WT}}$ or $\mathrm{GFAP}^{\mathrm{R} 79 \mathrm{H}}$ was expressed in fly glial cells (Fig. 9A,B). Autophagy induction increased with age, with modest induction present at $1 \mathrm{~d}$ (supplemental Fig. 5, longer exposure of Fig. 9A, available at www.jneurosci.org as supplemental material) and more substantial induction at 10 and $20 \mathrm{~d}$ of age. Double-label immunostaining confirmed the glial nature of cells containing autophagic vacuoles labeled with GFP-LC3 (Fig. 9C-F). To probe the relationship between protein misfolding, oxidative stress, and activation of autophagy, we examined GFP-LC3 levels in genetically modified backgrounds (Fig. $9 G-J$ ). We found that reduction of GFAP toxicity and aggregation mediated by increased expression of Cryab or human Hsp70 reduced activation of autophagy (Fig. 9G,J). Similarly, increasing the levels of oxidative stress by reducing Cat or Sod levels using heterozygous null alleles of Cat and Sod increased levels of GFP-LC3 in GFAP ${ }^{\mathrm{R} 79 \mathrm{H}}$ transgenic flies (Fig. $9 \mathrm{H}, J)$. In contrast, reduced $\mathrm{GFAP}^{\mathrm{R} 79 \mathrm{H}}$ toxicity present in flies overexpressing Eaat 1 did not substantially alter the autophagic response (Fig. 9I,J). 


\section{Discussion}

Analysis of Drosophila models has proven a useful approach for studying human neurological disorders. Because the complexity of human genetics has made isolating disease-linked genes in people a relatively slow process, we and others have begun using simple model organisms as an alternative (Feany and Bender, 2000; Wittmann et al., 2001; Jackson et al., 2002; Bonini and Fortini, 2003). In addition, short generation time and facile genetics make simple model organisms an attractive complement to vertebrate experimental models for mechanistic studies. We have thus now created a model of Alexander disease in Drosophila by expressing wild-type and disease-linked mutant versions of human GFAP in glial cells. A similar approach of expressing human aggregating proteins linked to degenerative diseases by a likely toxic gain-of-function mechanism has been successful in modeling Parkinson's disease (Feany and Bender, 2000), Alzheimer's disease (Wittmann et al., 2001; Jackson et al., 2002), and polyglutamine disorders in Drosophila (Bonini and Fortini, 2003).

Our Alexander disease model replicates key features of the human disorder. Rosenthal fibers are a major hallmark of Alexander disease pathology. These eosinophilic, often beaded structures are proteinaceous inclusions found within astrocytes. GFAP is a primary constituent of Rosenthal fibers, but the inclusions also contain the small heat shock protein Cryab $(\alpha \mathrm{B}$ crystallin) (Tomokane et al., 1991; Head and Goldman, 2000). Rosenthal fibers are electron dense and osmiophilic at the electron microscopic level (Herndon et al., 1970). When we express mutant forms of GFAP in Drosophila, we observe inclusions that bear strong similarities to authentic Rosenthal fibers. Inclusions are eosinophilic and morphology ranges from round to beaded, as seen at both the light and electron microscopic levels (Fig. 2) (supplementary Fig. 2, available at www.jneurosci.org as supplemental material). Fly inclusions contain Cryab (Fig. 2G-J) and are dense and osmiophilic under electron microscopy.

The strong aggregation propensity of GFAP and formation of Rosenthal-like inclusion bodies in our model prompted us to determine whether aggregation promoted cellular toxicity. We found that expression of several distinct heat shock proteins, including Cryab, Hsp26, Hsp27, and Hsp70, all decreased toxicity of GFAP in our flies. In each case, there was a concomitant increase in the solubility of GFAP as measured the number of inclusions and also biochemically (Figs. 3, 4). These findings correlate well with the ability of overexpressed Cryab to decrease toxicity in Alexander disease

A
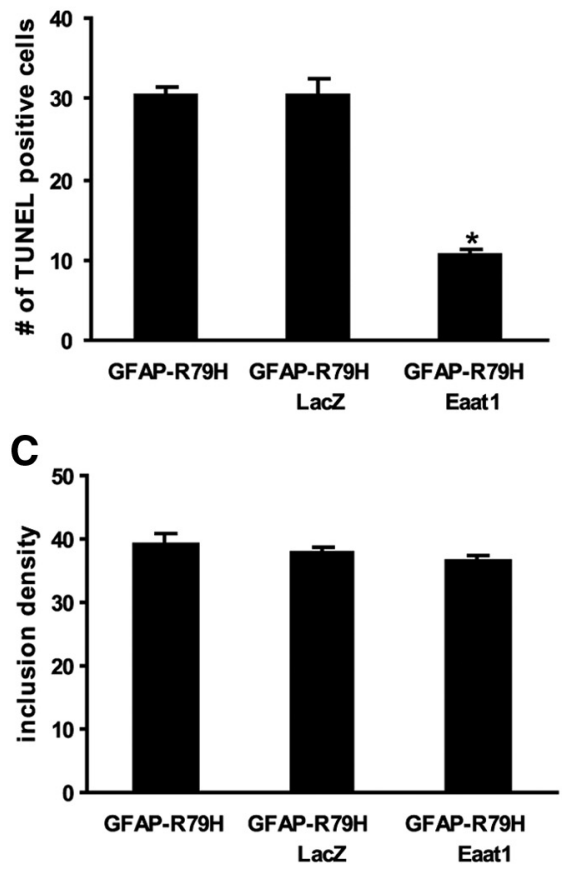

D
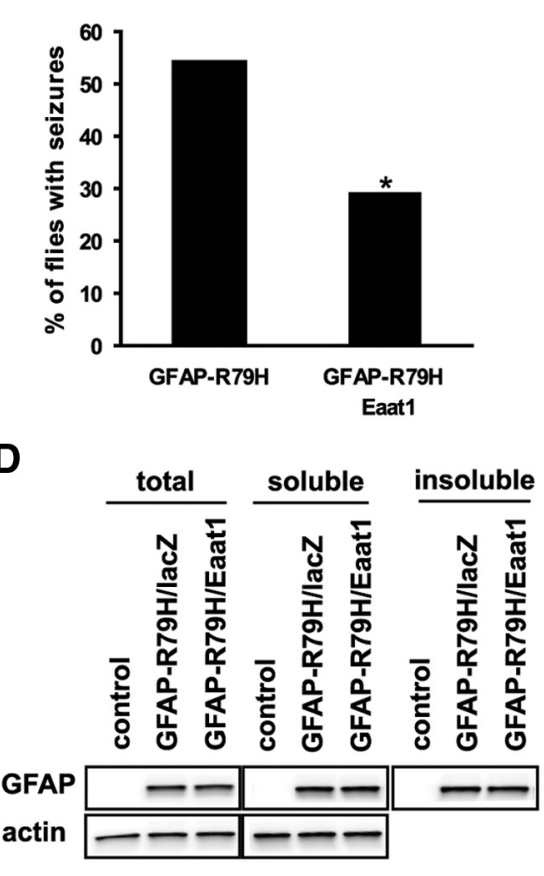

Figure 6. Overexpression of glial glutamate transporter rescues GFAP toxicity but does not change GFAP solubility. A, Decreased numbers of TUNEL-positive cells are present when GFAP ${ }^{\mathrm{R} 79 \mathrm{H}}$ is coexpressed with the Drosophila glial glutamate transporter Eaat1. Flies are $20 \mathrm{~d}$ old. $n=6$ for each genotype. ${ }^{*} p<0.01$ versus controls (GFAP ${ }^{\mathrm{R} 79 \mathrm{H}}$ and GFAP ${ }^{\mathrm{R} 79 \mathrm{H}} / \mathrm{lacZ}$ ). $\boldsymbol{B}$, 0verexpression of the glutamate transporter in glia of GFAP ${ }^{\mathrm{R} 79 \mathrm{H}}$ flies (GFAP ${ }^{\mathrm{R} 79 \mathrm{H}} /$ Eaat1) reduces the percentage of flies with seizures. Flies are $1 \mathrm{~d}$ old. $n=$ 90 (GFAP ${ }^{\mathrm{R} 79 H}$ ) and $n=148$ (GFAP ${ }^{\mathrm{R} 79 H} /$ Eaat1). ${ }^{*} p<0.01$. C, Expression of Eaat1 does not influence inclusion number. $n=6$ for each genotype. Flies are $20 \mathrm{~d}$ old. D, Overexpression of the glutamate transporter does not change GFAP solubility compared with $G F^{\mathrm{R} 79 H}$ alone (top). Flies are $1 \mathrm{~d}$ old. The blot was reprobed with an antibody to actin to demonstrate equivalent protein loading (soluble fractions; bottom). Genotypes are as follows: control: repo-GAL4/+; GFAP ${ }^{\text {R79H: }}$ repo-GAL4, UAS-GFAP ${ }^{R 79 H} /+$;

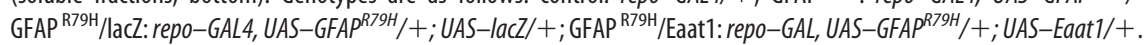

A

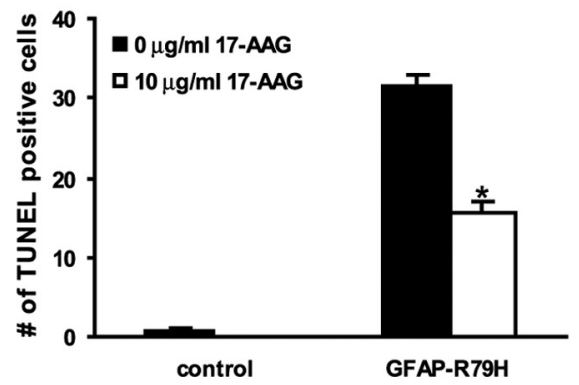

B

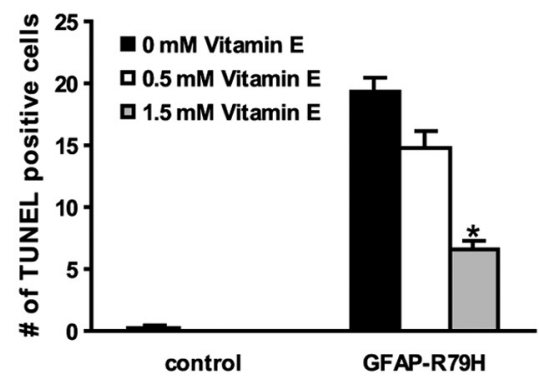

Figure 7. Pharmacological modulation of heat shock proteins and antioxidant defense suppresses GFAP toxicity. A, Administration of 17-AAG for $20 \mathrm{~d}$ after eclosion suppresses GFAP toxicity in vivo. Flies fed with $10 \mu \mathrm{g} / \mathrm{ml} 17-A A G$ show significantly reduced toxicity compared with flies fed with solvent (DMSO) alone. $n=6$ for each data point. ${ }^{*} p<0.01$. $B$, Administration of vitamin $\mathrm{E}$ for $20 \mathrm{~d}$ after eclosion suppresses GFAP toxicity in vivo in a dose-dependent manner. Flies fed with $0.5 \mathrm{~mm}$ vitamin $\mathrm{E}$ display a trend ( $p=0.02$ ) toward suppression of toxicity, whereas flies fed with $1.5 \mathrm{~mm}$ vitamin E show significant toxicity suppression compared with flies fed with solvent (soybean oil) alone. $n=6$ for each data point. ${ }^{*} p<0.01$. Genotypes are as follows: control: repo-GAL4/+;GFAP ${ }^{\mathrm{R} 79 H}$ : repo-GAL4, UAS-GFAP $P^{R 79 H} /+$.

model mice (Hagemann et al., 2009). However, because Cryab can inhibit cleavage of caspase 3 , influence diverse signaling pathways, and stabilize the actin cytoskeleton, among other functions (Arrigo et al., 2007; Steinman, 2009), our data extend previous work in mouse models by supporting a protein misfolding mechanism in modulation of GFAP toxicity. Furthermore, the ability of the chemical Hsp90 inhibitor 17-AAG to rescue toxicity when administered orally (Fig. $7 A$ ) suggests that protein misfolding may be an effective therapeutic target in Alexander disease. Be- 
A

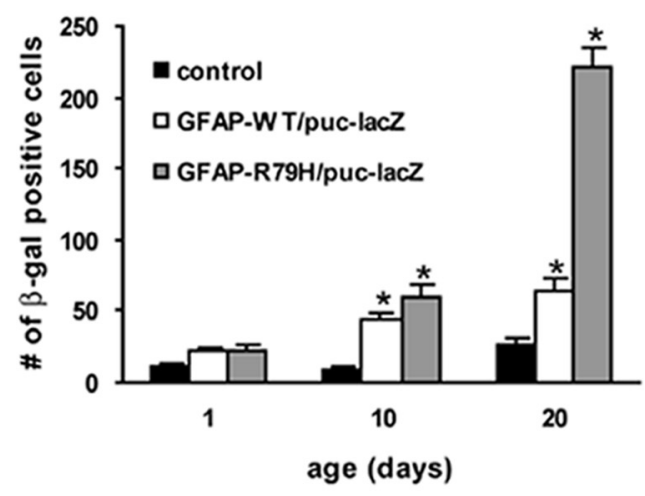

J

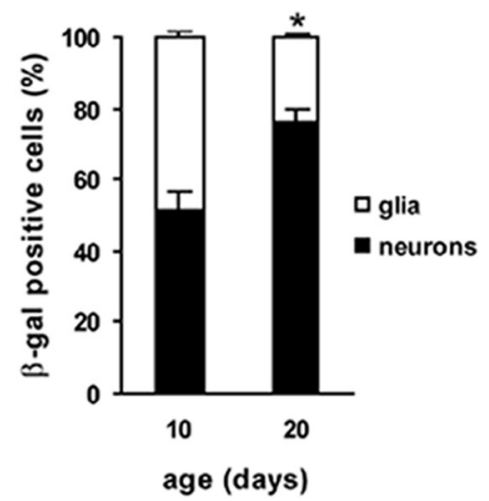

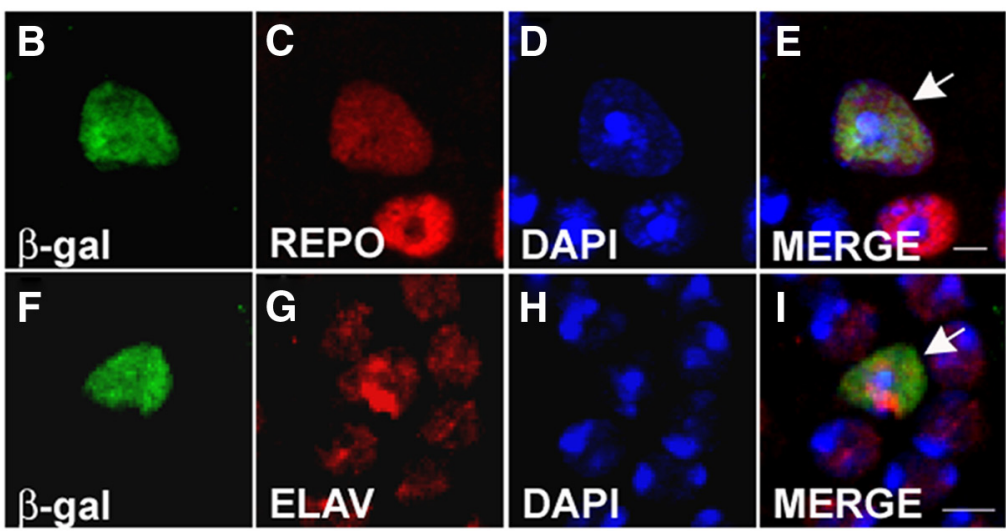

Figure 8. JNK pathway activation in GFAP transgenic flies. $\boldsymbol{A}$, JNK activation is time and genotype dependent as measured using a puc-lacZ reporter and immunostaining in tissue sections. $n=6$ for each genotype. Serial frontal sections of the entire brains (central body and medulla) were assayed. * $p<0.01$ versus control. Genotypes are as follows: control: repo-GAL4/puc-lacZ;

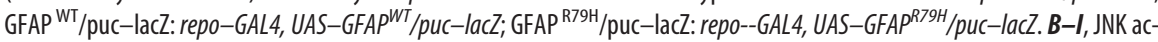
tivation as reported by expression of puc-driven $\beta$-galactosidase $(\beta$-gal; $\boldsymbol{B}, \boldsymbol{F})$ is detected in both glia and neurons of GFAP transgenic flies. REPO marks glial cells ( $\boldsymbol{C}$ ) and ELAV shows neurons $(\boldsymbol{G})$. Nuclei are counterstained with DAPI $(\boldsymbol{D}, \boldsymbol{H})$. Colocalization of $\beta$-galactosidase with REPO or ELAV is shown in $\boldsymbol{E}$ and $\boldsymbol{I}$ (arrows). The central body is shown. Flies are $20 \mathrm{~d}$ old. Scale bar, $2 \mu \mathrm{m}$. $J$, Quantification of $\beta$-galactosidase-positive cells in GFAP transgenic flies shows more JNK activation in neurons at day 20 compared with day 10 . Serial frontal sections of the entire brains (central body and medulla) were assayed. $n=6$ for each data point. ${ }^{*} p<0.01$ (Student's $t$ test).

cause both inclusion formation and cell death occurred in a widespread pattern throughout the brain, we are not currently able to dissect out local versus global effects of glial protein aggregation.

We were also able to significantly rescue toxicity of GFAP by feeding transgenic flies the antioxidant vitamin $\mathrm{E}$ (Fig. $7 \mathrm{~B}$ ). A role for oxidative stress in mediating toxicity was further supported by genetic modulation of antioxidant defense pathways (Fig. 5). These findings correlate well with upregulation of antioxidant defense genes and increased expression of a reporter construct carrying the gene for human placental alkaline phosphatase regulated by the antioxidant response element (ARE-hPAP) in GFAP transgenic mice (Hagemann et al., 2005, 2006). Our findings further support a causal role for oxidative stress in promoting toxicity of GFAP. Interestingly, however, oxidative stress may act through a mechanism other than promoting GFAP aggregation because there was no detectable change in the number of inclusion bodies or in biochemically insoluble species of GFAP in the presence of oxidative stress modifiers (Fig. 5C,D).

In contrast, we do see that reducing levels of Cat and Sod influences the activation of autophagy in our model (Fig. 9H, J). Protein misfolding also influences autophagy activation, with reduced levels of autophagy correlating with less misfolded GFAP
(Fig. 9G,J). Thus, both oxidative stress and misfolded GFAP promote activation of the autophagic response. Autophagy presumably acts to protect cells from GFAP toxicity by promoting clearance of the protein, although a definitive role for autophagy in modulating the toxicity of GFAP will require additional work. We also show here that increasing expression of the glial glutamate transporter protects from GFAP toxicity but does not alter protein aggregation (Fig. 6C,D) or autophagy (Fig. 9I,J). Thus, impairment of glutamate transport may be a downstream mechanism of cellular toxicity. In GFAP transgenic mice, overexpression of Cryab partially restores Glt1 transcript levels (Hagemann et al., 2009), consistent with altered glial glutamate transport as a downstream target of GFAP misfolding.

A role for glutamate toxicity in our model is also supported by degeneration of neurons expressing glutamate receptors and rescue of GFAP toxicity by overexpression of glial glutamate transporter Eaat1 (Fig. $1 E, 6 A, B$ ). In future work, it will be useful to extend the current work by documenting that glutamate receptorexpressing neurons are preferentially protected from glial GFAP toxicity. These studies will require development of additional reagents. Neurodegeneration is a consistent feature of Alexander disease in patients (van der Knaap et al., 2005; Brenner et al., 2009). Our data support a non-cell-autonomous mechanism of neuronal loss that reflects early dysfunction of glial cells, followed by a neuronal response (Fig. $8 \mathrm{~J}$ ). Dysregulation of neuronal genes also follows glial cell abnormalities in transgenic mice (Hagemann et al., 2005). Although the mechanisms leading to neuronal death remain essentially undefined, we observe significant JNK activation in neurons, consistent with a stress response.

Here we provide multiple lines of evidence supporting commonalities among our Drosophila model of Alexander disease, GFAP transgenic mouse models of the disorder, and the human disease itself. Thus, the fly model appears to hold significant promise for additional dissection of the mechanisms by which GFAP promotes glial and neuronal toxicity in disease. These findings may reflect important similarities in glial biology between Drosophila and mammalian systems. Drosophila glia subserve many of the same functions as their vertebrate counterparts, including regulation of path finding during development, bloodbrain barrier formation and maintenance, and glutamate buffering (Freeman et al., 2003; Rival et al., 2004; Pereanu et al., 2005). It is important to note, however, that differences exist between vertebrate and fly glia as well. First, Drosophila do not have intermediate filaments, including GFAP. Although we postulate a gain-of-function mechanism in Alexander disease, our model may not be able to address any component of loss of intermediate filament function toxicity present in the disease. Second, although fly glia do ensheath and support axons, these 
A

\begin{tabular}{lll} 
Day 1 & Day 10 & Day 20 \\
${ } }$ & \\
\hline
\end{tabular}

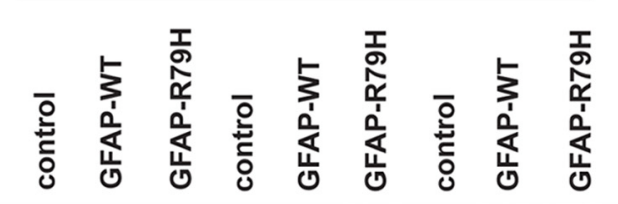
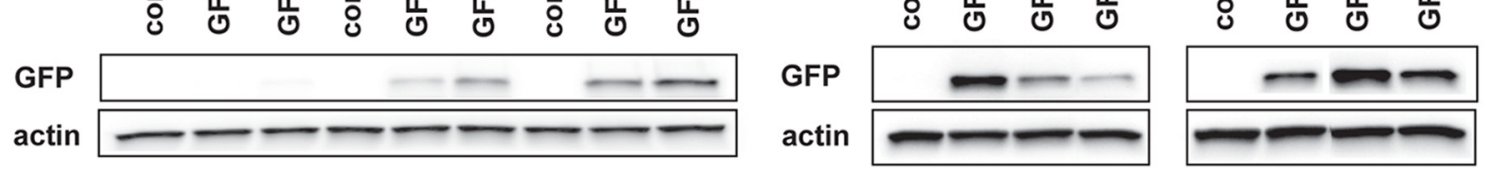

I GFP-LC3
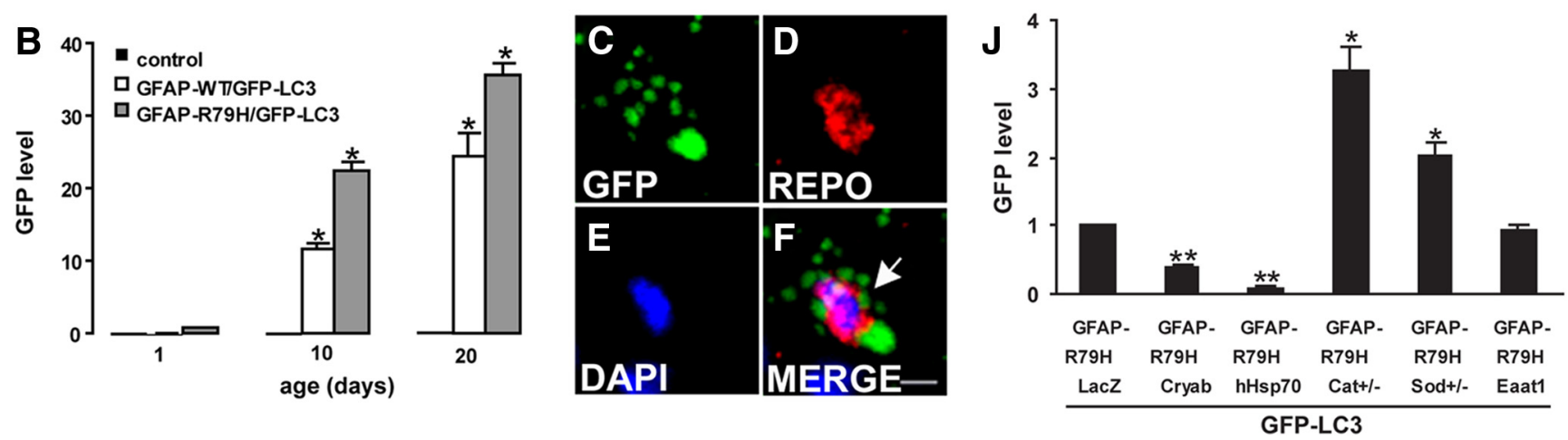

Figure 9. Autophagy in GFAP transgenic flies. $A, B$, Induction of autophagy as measured with a GFP-LC3 transgene depends on age and genotype (top). The blot was reprobed with an antibody to actin to demonstrate equivalent protein loading (bottom). Quantification of GFP levels in $B$ is normalized to actin levels. ${ }^{*} p<0.01$. Genotypes are as follows: control: repo-GAL4/UAS-GFP-LC3;

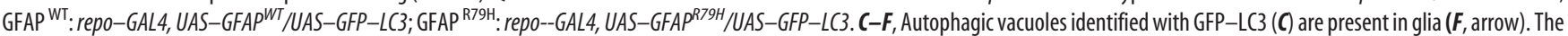
glia cell is marked with REPO (D). Nuclei are counterstained with DAPI (E). The central body is shown. Flies are $10 \mathrm{~d}$ old. Scale bar, $2 \mu \mathrm{m}$. G, Overexpression of heat shock proteins Cryab and human $\mathrm{Hsp} 70$ in GFAP ${ }^{\mathrm{R} 7 \mathrm{H}}$ flies reduces autophagy. $\boldsymbol{H}$, Decreasing levels of Cat and Sod using heterozygous null alleles of Cat and Sod in GFAP ${ }^{\mathrm{R} 7 \mathrm{H}}$ flies increases activation of autophagy. $\boldsymbol{I}$, 0 verexpression of glial glutamate transporter in GFAP ${ }^{\mathrm{R} 9 \mathrm{H}}$ flies does not strongly influence autophagy activation. Flies are $1 \mathrm{~d}$ old. Blots were reprobed with an antibody recognizing actin as a loading control (bottom). J, Quantification of GFP levels in figure $\mathbf{G}-\mathbf{I}$ is normalized to actin levels. ${ }^{*} p<0.05,{ }^{* *} p<0.01$ compared with GFAP R79H/LacZ/GFPLC3. Genotypes are as follows: control: repo-GAL4/

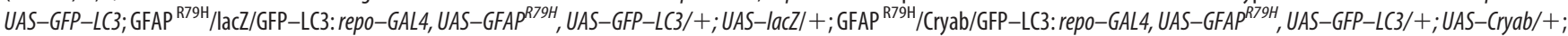

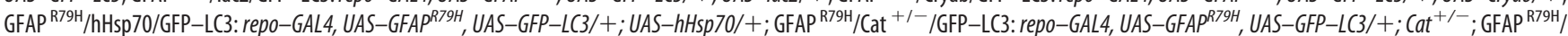
$\mathrm{Sod}^{+/-}$/GFP-LC3: repo-GAL4, UAS-GFAP ${ }^{R 79 H}$, UAS-GFP-LC3/+; Sod ${ }^{+/-}$; GFAP ${ }^{\text {R79H/Eaat1/GFP-LC3: repo-GAL4, UAS-GFAP }}{ }^{R 79 H}$, UAS-GFP-LC3/+; UAS-Eaat1/+.

wrappings typically form a single layer, and the multilayer structures typical of dense myelin in vertebrates are infrequent in flies. The lack of myelin may have particular importance in modeling Alexander disease because of the prominent white matter pathology in younger patients. Thus, differences between fly and vertebrate glia may limit the utility of our model in the future.

In summary, we have described a Drosophila model for Alexander disease, which replicates key features of the human disease, including formation of abundant Rosenthal fiber-like inclusions. We have further used a genetic approach to support strongly a causal role for abnormal protein aggregation, oxidative stress, and inadequate glial glutamate buffering in GFAP toxicity in vivo. These findings correlate well with previous work in GFAP transgenic mice and in cell culture models of the disorder. We have also begun to explore the complex neuronal-glial interplay that mediates neurodegeneration in our model. Because glia, including astrocytes, undergo structural and functional changes in a variety of neurological diseases, our findings and our model may have wider implications and utility.

\section{References}

Arrigo AP, Simon S, Gibert B, Kretz-Remy C, Nivon M, Czekalla A, Guillet D, Moulin M, Diaz-Latoud C, Vicart P (2007) Hsp27 (HspB1) and alphaBcrystallin (HspB5) as therapeutic targets. FEBS Lett 581:3665-3674.

Azad MB, Chen Y, Gibson SB (2009) Regulation of autophagy by reactive oxygen species (ROS): implications for cancer progression and treatment. Antioxid Redox Signal 11:777-790.
Benzer S (1971) From the gene to behavior. JAMA 218:1015-1022.

Bonini NM, Fortini ME (2003) Human neurodegenerative disease modeling using Drosophila. Annu Rev Neurosci 26:627-656.

Brand AH, Perrimon N (1993) Targeted gene expression as a means of altering cell fates and generating dominant phenotypes. Development 118:401-415.

Brenner M, Johnson AB, Boespflug-Tanguy O, Rodriguez D, Goldman JE, Messing A (2001) Mutations in GFAP, encoding glial fibrillary acidic protein, are associated with Alexander disease. Nat Genet 27:117-120.

Brenner M, Goldman JE, Quinlan RA, Messing A (2009) Alexander disease: a genetic disorder of astrocytes. In: Astrocytes in pathophysiology of the nervous system (Parpura V, Haydon PG), pp 591-648. Boston: Springer.

Der Perng M, Su M, Wen SF, Li R, Gibbon T, Prescott AR, Brenner M, Quinlan RA (2006) The Alexander disease-causing glial fibrillary acidic protein mutant, R416W, accumulates into Rosenthal fibers by a pathway that involves filament aggregation and the association of alpha B-crystallin and HSP27. Am J Hum Genet 79:197-213.

Feany MB, Bender WW (2000) A Drosophila model of Parkinson's disease. Nature 404:394-398.

Freeman MR, Delrow J, Kim J, Johnson E, Doe CQ (2003) Unwrapping glial biology: $\mathrm{Gcm}$ target genes regulating glial development, diversification, and function. Neuron 38:567-580.

Fujikake N, Nagai Y, Popiel HA, Okamoto Y, Yamaguchi M, Toda T (2008) Heat shock transcription factor 1-activating compounds suppress polyglutamine-induced neurodegeneration through induction of multiple molecular chaperones. J Biol Chem 283:26188-26197.

Ganetzky B, Wu CF (1982) Drosophila mutants with opposing effects on nerve excitability: genetic and spatial interactions in repetitive firing. J Neurophysiol 47:501-514.

García-Arencibia M, Hochfeld WE, Toh PP, Rubinsztein DC (2010) Au- 
tophagy, a guardian against neurodegeneration. Semin Cell Dev Biol 21:691-698.

Ghosh S, Feany MB (2004) Comparison of pathways controlling toxicity in the eye and brain in Drosophila models of human neurodegenerative diseases. Hum Mol Genet 13:2011-2018.

Hagemann TL, Gaeta SA, Smith MA, Johnson DA, Johnson JA, Messing A (2005) Gene expression analysis in mice with elevated glial fibrillary acidic protein and Rosenthal fibers reveals a stress response followed by glial activation and neuronal dysfunction. Hum Mol Genet 14:2443-2458.

Hagemann TL, Connor JX, Messing A (2006) Alexander disease-associated glial fibrillary acidic protein mutations in mice induce Rosenthal fiber formation and a white matter stress response. J Neurosci 26:11162-11173.

Hagemann TL, Boelens WC, Wawrousek EF, Messing A (2009) Suppression of GFAP toxicity by alphaB-crystallin in mouse models of Alexander disease. Hum Mol Genet 18:1190-1199.

Head MW, Goldman JE (2000) Small heat shock proteins, the cytoskeleton, and inclusion body formation. Neuropathol Appl Neurobiol 26:304-312.

Herndon RM, Rubinstein LJ, Freeman JM, Mathieson G (1970) Light and electron microscopic observations on Rosenthal fibers in Alexander's disease and in multiple sclerosis. J Neuropathol Exp Neurol 29:524-551.

Jackson GR, Wiedau-Pazos M, Sang TK, Wagle N, Brown CA, Massachi S, Geschwind DH (2002) Human wild-type tau interacts with wingless pathway components and produces neurofibrillary pathology in Drosophila. Neuron 34:509-519.

Khurana V, Lu Y, Steinhilb ML, Oldham S, Shulman JM, Feany MB (2006) TOR-mediated cell-cycle activation causes neurodegeneration in a Drosophila tauopathy model. Curr Biol 16:230-241.

Liedtke W, Edelmann W, Bieri PL, Chiu FC, Cowan NJ, Kucherlapati R, Raine CS (1996) GFAP is necessary for the integrity of CNS white matter architecture and long-term maintenance of myelination. Neuron 17:607-615.

Martín-Blanco E, Gampel A, Ring J, Virdee K, Kirov N, Tolkovsky AM, Martinez-Arias A (1998) puckered encodes a phosphatase that mediates a feedback loop regulating JNK activity during dorsal closure in Drosophila. Genes Dev 12:557-570.

McCall MA, Gregg RG, Behringer RR, Brenner M, Delaney CL, Galbreath EJ, Zhang CL, Pearce RA, Chiu SY, Messing A (1996) Targeted deletion in astrocyte intermediate filament (GFAP) alters neuronal physiology. Proc Natl Acad Sci U S A 93:6361-6366.

Messing A, Head MW, Galles K, Galbreath EJ, Goldman JE, Brenner M (1998) Fatal encephalopathy with astrocyte inclusions in GFAP transgenic mice. Am J Pathol 152:391-398.

Pekny M, Levéen P, Pekna M, Eliasson C, Berthold CH, Westermark B, Betsholtz C (1995) Mice lacking glial fibrillary acidic protein display astrocytes devoid of intermediate filaments but develop and reproduce normally. EMBO J 14:1590-1598.

Pereanu W, Shy D, Hartenstein V (2005) Morphogenesis and proliferation of the larval brain glia in Drosophila. Dev Biol 283:191-203.

Rival T, Soustelle L, Strambi C, Besson MT, Iché M, Birman S (2004) Decreasing glutamate buffering capacity triggers oxidative stress and neuropil degeneration in the Drosophila brain. Curr Biol 14:599-605.

Rothstein JD (2009) Current hypotheses for the underlying biology of amyotrophic lateral sclerosis. Ann Neurol 65 [Suppl 1]:S3-S9.

Rusten TE, Lindmo K, Juhász G, Sass M, Seglen PO, Brech A, Stenmark H (2004) Programmed autophagy in the Drosophila fat body is induced by ecdysone through regulation of the PI3K pathway. Dev Cell 7:179-192.
Schmid A, Hallermann S, Kittel RJ, Khorramshahi O, Frölich AM, Quentin C, Rasse TM, Mertel S, Heckmann M, Sigrist SJ (2008) Activity-dependent site-specific changes of glutamate receptor composition in vivo. Nat Neurosci 11:659-666.

Seal RP, Daniels GM, Wolfgang WJ, Forte MA, Amara SG (1998) Identification and characterization of a cDNA encoding a neuronal glutamate transporter from Drosophila melanogaster. Receptors Channels 6:51-64.

Sepp KJ, Auld VJ (1999) Conversion of lacZ enhancer trap lines to GAL4 lines using targeted transposition in Drosophila melanogaster. Genetics 151:1093-1101.

Sepp KJ, Schulte J, Auld VJ (2001) Peripheral glia direct axon guidance across the CNS/PNS transition zone. Dev Biol 238:47-63.

Shibuki K, Gomi H, Chen L, Bao S, Kim JJ, Wakatsuki H, Fujisaki T, Fujimoto K, Katoh A, Ikeda T, Chen C, Thompson RF, Itohara S (1996) Deficient cerebellar long-term depression, impaired eyeblink conditioning, and normal motor coordination in GFAP mutant mice. Neuron 16:587-599.

Song J, Parker L, Hormozi L, Tanouye MA (2008) DNA topoisomerase I inhibitors ameliorate seizure-like behaviors and paralysis in a Drosophila model of epilepsy. Neuroscience 156:722-728.

Steinman L (2009) The gray aspects of white matter disease in multiple sclerosis. Proc Natl Acad Sci U S A 106:8083-8084.

Tang G, Xu Z, Goldman JE (2006) Synergistic effects of the SAPK/JNK and the proteasome pathway on glial fibrillary acidic protein (GFAP) accumulation in Alexander disease. J Biol Chem 281:38634-38643.

Tang G, Yue Z, Talloczy Z, Hagemann T, Cho W, Messing A, Sulzer DL, Goldman JE (2008) Autophagy induced by Alexander disease-mutant GFAP accumulation is regulated by $\mathrm{p} 38 / \mathrm{MAPK}$ and mTOR signaling pathways. Hum Mol Genet 17:1540-1555.

Tang G, Perng MD, Wilk S, Quinlan R, Goldman JE (2010) Oligomers of mutant glial fibrillary acidic protein (GFAP) inhibit the proteasome system in Alexander disease astrocytes, and the small heat shock protein $\alpha \mathrm{B}$-crystallin reverses the inhibition. J Biol Chem 285:10527-10537.

Tian R, Wu X, Hagemann TL, Sosunov AA, Messing A, McKhann GM, Goldman JE (2010) Alexander disease mutant glial fibrillary acidic protein compromises glutamate transport in astrocytes. J Neuropathol Exp Neurol 69:335-345.

Tomokane N, Iwaki T, Tateishi J, Iwaki A, Goldman JE (1991) Rosenthal fibers share epitopes with alpha B-crystallin, glial fibrillary acidic protein, and ubiquitin, but not with vimentin. Immunoelectron microscopy with colloidal gold. Am J Pathol 138:875-885.

van der Knaap MS, Salomons GS, Li R, Franzoni E, Gutiérrez-Solana LG, Smit LM, Robinson R, Ferrie CD, Cree B, Reddy A, Thomas N, Banwell B, Barkhof F, Jakobs C, Johnson A, Messing A, Brenner M (2005) Unusual variants of Alexander's disease. Ann Neurol 57:327-338.

Wang MC, Bohmann D, Jasper H (2005) JNK extends life span and limits growth by antagonizing cellular and organism-wide responses to insulin signaling. Cell 121:115-125.

Waza M, Adachi H, Katsuno M, Minamiyama M, Tanaka F, Sobue G (2006) Alleviating neurodegeneration by an anticancer agent: an Hsp90 inhibitor (17-AAG). Ann N Y Acad Sci 1086:21-34.

Wittmann CW, Wszolek MF, Shulman JM, Salvaterra PM, Lewis J, Hutton M, Feany MB (2001) Tauopathy in Drosophila: neurodegeneration without neurofibrillary tangles. Science 293:711-714. 